\title{
PROMOVENDO A PROFISSÃO DO CIENTISTA A PARTIR DE UM PROJETO DE EXTENSÃO UNIVERSITÁRIA.
}

\section{PROMOTING THE SCIENTIST'S PROFESSION THROUGH A UNIVERSITY EXTENTION PROJECT.}

\author{
TEIXEIRA, Larissa Marques Pires ${ }^{1}$ \\ ARAUJO, Juliana Magalhães ${ }^{2}$ \\ CREED, Joel Christopher ${ }^{3}$
}

\section{RESUMO}

A ciência deve ser cada vez mais valorizada, incentivada e acessível dentro e fora do meio acadêmico. O apoio popular de quem não tem contato com a ciência no seu dia a dia, é fundamental nesse processo. O Projeto "Pra que Serve?" é um projeto de extensão universitária que tem como objetivo trazer a debate a importância da ciência, sobretudo em ambiente marinho, em uma cidade litorânea como o Rio de Janeiro, e contribuir para a valorização da pesquisa científica, possibilitando, de forma simples e acessível, vivências de pesquisa e acesso a conteúdo científico. A oficina que constitui a metodologia do Projeto pode ser aplicada de duas formas, visitas escolares programadas e eventos de ciência abertos ao público espontâneo. No presente trabalho, nós relatamos a experiência vivenciada no Espaço de Desenvolvimento Infantil Professora Solange Conceição Tricarico na comunidade da Maré, no Instituto Benjamin Constant, escola que atende crianças e adolescentes cegos, surdocegos, com baixa visão e deficiência múltipla e nos eventos Bio na Rua 2018 e 2019, no Parque Madureira, localizado na zona norte carioca. Ao longo da oficina, foram registrados por meio de fotografias, momentos de interação, para que pudéssemos analisar diferentes dimensões de atuação do projeto e a resposta daqueles que participavam. A curiosidade sobre o material utilizado na pesquisa marinha foi fundamental para despertar o interesse do público, independente da faixa etária e do local da oficina. Detectamos diferentes interações durante as oficinas, sendo a observação e/ou atenção às explicações a mais recorrente. Responder "O que é?" e "Pra que serve?" a ciência, considerando

\footnotetext{
${ }^{1}$ Universidade do Estado do Rio de Janeiro - UERJ / Programa de Pós-Graduação em Ecologia e Evolução PPGEE-UERJ. Rio de Janeiro, RJ, Brasil. ORCID: https://orcid.org/0000-0001-5885-7777 e-mail: larissamarques@ymail.com

${ }^{2}$ Universidade do Estado do Rio de Janeiro - UERJ / Programa de Pós-Graduação em Ecologia e Evolução PPGEE-UERJ. Rio de Janeiro, RJ, Brasil. ORCID: https://orcid.org/0000-0002-6051-7381 e-mail: dearaujojm@gmail.com

${ }^{3}$ Universidade do Estado do Rio de Janeiro - UERJ / Instituto de Biologia Roberto Alcantara Gomes IBRAG / Programa de Pós-Graduação em Ecologia e Evolução - PPGEE-UERJ. Rio de Janeiro, RJ, Brasil. ORCID: https://orcid.org/0000-0002-1722-0806 e-mail: jcreed@uerj.br
} 
DOI: $10.12957 / \mathrm{e}-\mathrm{mosaicos} .2021 .47898$

as ações do Projeto despertou nos participantes grande engajamento nos temas científicos e curiosidade sobre a profissão do(a) cientista. A partir dos resultados positivos apresentados no presente trabalho daremos continuidade às ações do Projeto, buscando ampliar o desenvolvimento qualitativo de práticas como essa.

Palavras-Chave: Ciência; Costão rochoso; Divulgação científica; Ecologia marinha; Popularização da ciência.

\section{ABSTRACT}

Science must be increasingly valued, encouraged and made more accessible to all, inside and outside the academic environment. The popular support of those who do not have contact with science on a daily basis is fundamental in this process. The project "Pra que serve?" is a university extension project that aims to bring to debate the importance of science, especially in the marine environment in a coastal city like Rio de Janeiro, and to contribute to the valorization of scientific research, enabling, in a simple and accessible way, experiences research and access to scientific content. The workshop can be applied in two ways, scheduled school visits and science events open to the spontaneous public. The workshop can be applied in two ways, namely, scheduled school visits and science events open to the spontaneous public. In the present work, we report the experience lived in the Space for Child Development Professora Solange Conceição Tricarico in the community of Maré, at the Instituto Benjamin Constant, a school that serves blind and deafblind children and adolescents, with low vision and multiple disabilities and in the "Bio na Rua" events 2018 and 2019, at Parque Madureira, located in the northern zone of Rio de Janeiro. Throughout the workshop, moments of interaction were recorded through photographs, so that we could analyze different dimensions of the project's performance and the response of those who participated. Curiosity about the material used in marine research was fundamental to arouse public interest, regardless of the age group and the location, and it was possible to detect several interactions during the workshops, with observation and / or attention to explanations being the most recurrent. Reply "What is it?" and "What is it for?" science through the Project's actions aroused in the participants a great commitment to scientific themes and curiosity about the scientist's profession. Based on the positive results presented in the present work, we will continue the Project's actions, seeking to expand the qualitative development of practices like this.

KeYwORDS: Marine ecology; Rocky shore; Science; Scientific Communication, Popularization of science. 
DOI: $10.12957 / \mathrm{e}-\mathrm{mosaicos} .2021 .47898$

\section{INTRODUÇÃO}

A divulgação científica se refere à difusão de informações em ciência, tecnologia e inovação, voltada, principalmente, para aqueles que não têm, obrigatoriamente, formação técnico-científica que permita compreender conceitos científicos sem esforço (BUENO, 2010). Difundir a ciência usando uma linguagem acessível aproxima a população dos trabalhos desenvolvidos no âmbito da ciência e tecnologia (C\&T) o que, além de estender informações para um público maior, esclarece sobre os serviços que a ciência pode prestar e aumenta, também, a confiança por aqueles responsáveis por fazer ciência.

ALBAGLI (1996) aponta diferentes objetivos que podem orientar o papel da divulgação científica, entre eles a ampliação do conhecimento e da compreensão a respeito do processo científico e sua lógica (educação), o desenvolvimento de uma opinião pública informada sobre os impactos do desenvolvimento científico e tecnológico sobre a sociedade, particularmente em áreas críticas do processo de tomada de decisões (cívico), e a ampliação da possibilidade e da qualidade de participação da sociedade na formulação de políticas públicas e na escolha de opções tecnológicas (mobilização popular).

$\mathrm{O}$ interesse de brasileiros e brasileiras por C\&T pode ser considerado satisfatório. No entanto, na mídia, o acesso aos conteúdos que envolvem esse tema ainda é escasso e as pessoas que afirmam ser interessadas em C\&T não assistem por exemplo, a programas de TV que abordem a temática. Tais dados mostram haver uma associação significativa entre manifestar-se interessado em C\&T e ter algum acesso à informação sobre tais temas (VELHO, 2017). Resultados como esses nos fazem questionar quais ações são necessárias para popularizar a ciência.

As Instituições de Ensino Superior (IES) desempenham papéis importantes em cultivar conhecimento e colocá-lo em benefício da sociedade (SCHWARTZMAN e CHRISTOPHE, 2008). No entanto, o conhecimento gerado raramente atravessa os limites da academia. A falta de um diálogo constante entre aqueles que fazem ciência e a sociedade gera dúvidas quanto à profissão do cientista e à importância do mesmo. A falta de informação do público leigo é o que o torna vulnerável a pseudociência, a manipulação e o artificialismo político. A maior parte das pesquisas no âmbito acadêmico é financiada com dinheiro público, o que torna ainda mais imprescindível o diálogo entre ciência e sociedade (TOSTES, 2006). Ainda que a importância e o impacto das descobertas científicas e de suas aplicações através da tecnologia como meio de desenvolvimento e de promoção do bem-estar sejam reconhecidos, a pesquisa científica ainda é encarada com apreensão e importantes dúvidas são levantadas com relação ao papel da ciência na sociedade (SALA, 2017).

A divulgação científica, na prática, não está restrita aos meios de comunicação de massa, inclui também o uso de livros didáticos, palestras de Ciências, histórias em 
DOI: $10.12957 / \mathrm{e}-\mathrm{mosaicos} .2021 .47898$

quadrinhos e folhetos para veiculação de informações científicas (BUENO, 2010). A educação em Ciências faz com que o aluno interprete o mundo desde o ponto de vista das ciências, maneje conceitos, leis e teorias científicas, e aborde problemas raciocinando, cientificamente, identificando aspectos históricos, epistemológicos, sociais e culturais das Ciências (MOREIRA, 2004). Independentemente do método adotado, a educação em ciências pode inspirar futuros cientistas e despertar nas pessoas atitudes típicas de um cientista: curiosidade intelectual, dúvida metódica, observação dos fatos e busca de relações causais (SCHWARTZMAN E CHRISTOPHE, 2009).

\section{"Projeto Pra que Serve?" O que faz um cientista que trabalha com o mar.}

A ciência deve ser cada vez mais valorizada, incentivada e estar acessível para todos, dentro e fora do meio acadêmico. $O$ apoio da população que não tem contato com a ciência no seu dia a dia, é fundamental nesse processo. A ciência funciona como ferramenta transformadora em termos sociais e econômicos, mas, em uma sociedade que, majoritariamente, desconhece o desenvolvimento dos saberes científicos, esse processo fica distante de uma realidade de avanços nesses mesmos termos. O Projeto "Pra que Serve?" é um projeto de extensão universitária que tem como principal objetivo divulgar a profissão do cientista que trabalha com o mar, enriquecendo o conhecimento que o público não acadêmico possui acerca da ciência, das etapas do trabalho de um cientista e da importância do desenvolvimento de pesquisas científicas. O projeto foi elaborado para diferentes públicos, desde o ambiente escolar até espaços públicos. Relatamos aqui a experiência que vivenciamos durante as oficinas de extensão, a avaliação acerca da resposta do público, os desafios que encontramos e as perspectivas futuras para dar continuidade ao projeto.

\section{Procedimentos metodológicos}

Para trazer à debate a importância da ciência, sobretudo no ambiente marinho em uma cidade litorâneo como o Rio de Janeiro, e reverter a atual situação desfavorável a ciência, contribuindo para a valorização da pesquisa científica no Brasil, o projeto "Pra que serve?" foi organizado de forma simples e plástica, adaptado a qualquer tipo de local e público com diferentes idades, deficientes visuais ou com baixa visão e pessoas não alfabetizadas. Desta forma, pretendemos alcançar locais com carência de centros e de instituições de pesquisa e de ensino, como comunidades periféricas e violentas. 
DOI: $10.12957 / \mathrm{e}-\mathrm{mosaicos} .2021 .47898$

\section{MATERIAL UTILIZADO}

Inicialmente, nós produzimos material audiovisual e material permanente com o tema "pesquisa no mar", confeccionado em feltro, EVA e materiais de texturas diferentes. Os modelos didáticos de organismos marinhos (Fig. 1) representam suas principais características morfológicas e são acessíveis ao manuseio pelo público, não dependendo somente do recurso visual. Produzimos um guia de identificação de espécies marinhas bentônicas, encontradas no litoral brasileiro, com foto e nome popular/científico de cada espécie (Fig. 2).

Figura 1: Modelos didáticos dos organismos marinhos confeccionados em feltro e EVA e tirinha em quadrinho sobre o trabalho de um cientista que trabalho com o mar.

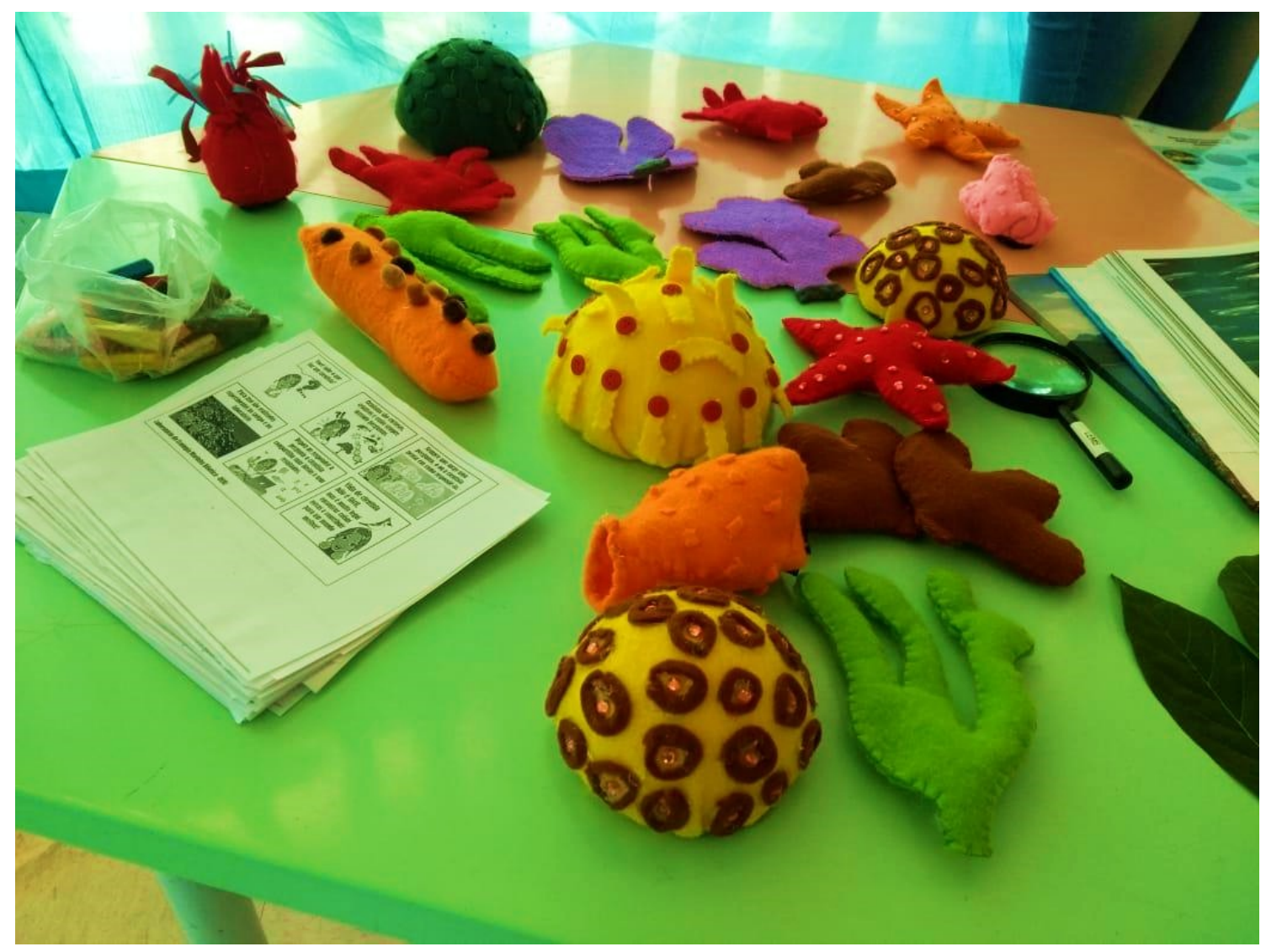

Foto: $\mathrm{O}(\mathrm{s})$ Autor(es) 


\section{e-Mosaicos}

Revista Multidisciplinar de Ensino, Pesquisa, Extensão e Cultura

DOI: $10.12957 / \mathrm{e}-\mathrm{mosaicos} .2021 .47898$

Figura 2: (A) Guia de espécies marinhas bentônicas encontradas no litoral brasileiro;(B) Guia sendo utilizado por aluno da pré-escola do Espaço de Desenvolvimento Infantil Professora Solange Conceição Tricarico.

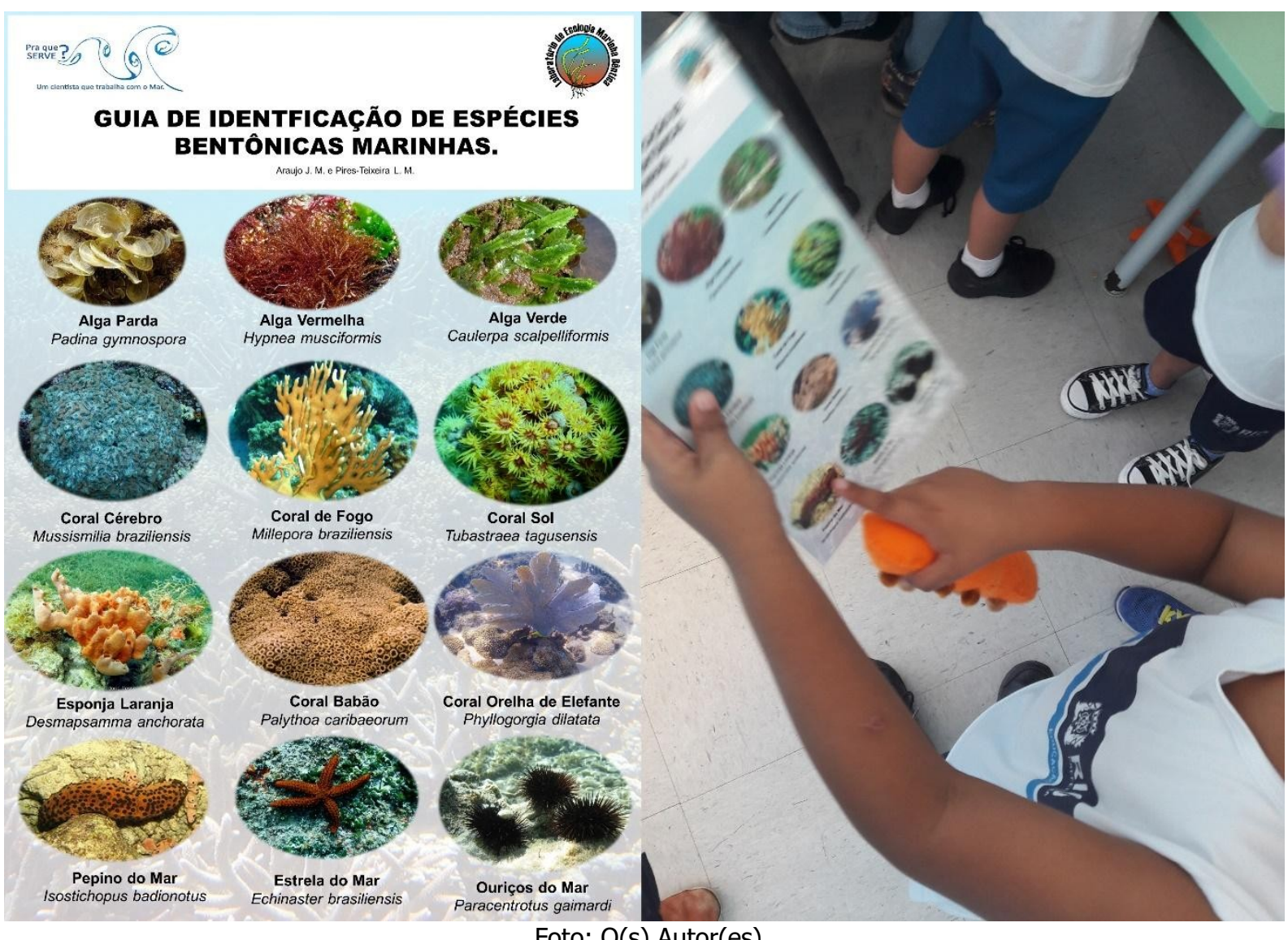

Foto: O(s) Autor(es)

Elaboramos uma tirinha em quadrinhos para ser pintada, relatando as atividades realizadas por um cientista que trabalha com o mar (Fig. 3). Esperamos atingir não só quem participou da oficina, mas também outras pessoas, com o manuseio desse material, que pode ser levado pelos participantes/alunos. A tirinha contém o endereço eletrônico das redes sociais vinculadas ao laboratório de pesquisa e o contato para agendamento da oficina. 


\section{Q e-Mosicos}

DOI: $10.12957 / \mathrm{e}-\mathrm{mosaicos} .2021 .47898$

Figura 3. Tirinha em quadrinho mostrando o trabalho de uma cientista que trabalha com o mar. Durante a oficina ela é distribuída em preto e branco para que os participantes possam colorir e assim perceber detalhes nos diálogos e peculiaridades dos organismos marinhos.
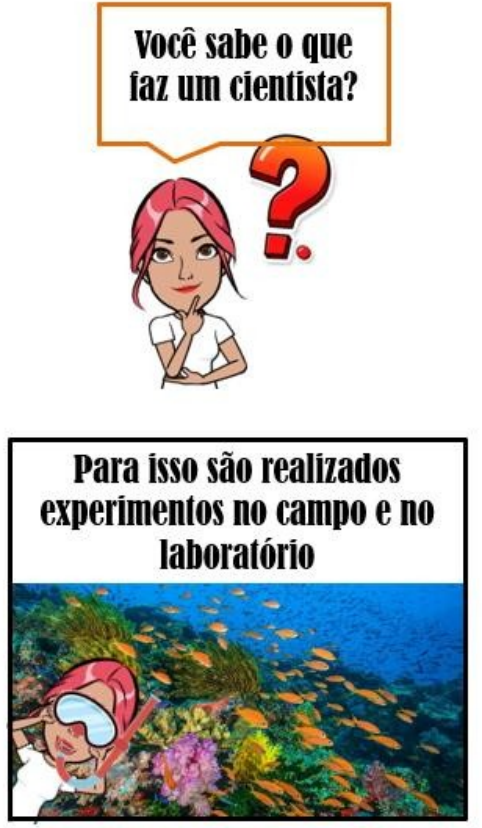
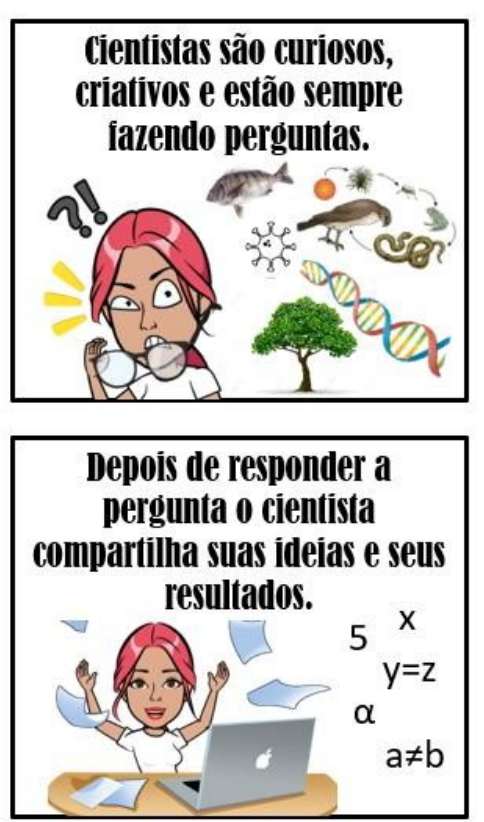

Foto: $\mathrm{O}(\mathrm{s})$ Autor(es)
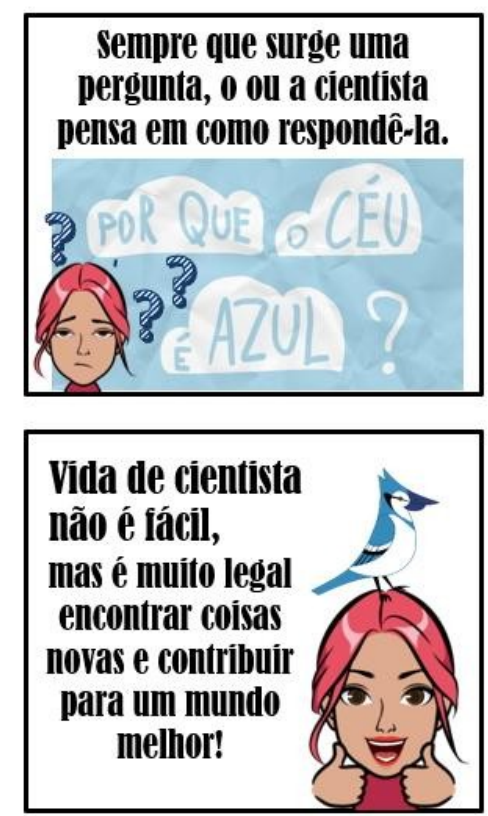

\section{Desenvolvimento dA Oficina}

A oficina pode ser aplicada de duas formas, sendo elas, visitas escolares programadas e eventos de ciência abertos ao público espontâneo. No presente trabalho, nós relatamos a experiência vivenciada no Espaço de Desenvolvimento Infantil Professora Solange Conceição Tricarico na comunidade da Maré (maio de 2019); no Instituto Benjamin Constant (IBC), escola que atende crianças e adolescentes cegos, surdocegos, com baixa visão e deficiência múltipla localizada no bairro da Urca (novembro de 2018); e nos eventos Bio na Rua 2018 (novembro de 2018) e Bio na Rua 2019 (dezembro de 2019), ambos no Parque Madureira, localizado no bairro de Madureira na zona norte carioca.

Nos eventos de divulgação científica, Bio na Rua, condensamos a oficina em informações rápidas e materiais lúdicos para manuseio do público. No IBC, apresentamos diferentes materiais, texturas, roupas de Neoprene (tecido usualmente usado para 0 mergulho) e material de mergulho, para que os alunos pudessem experimentar o trabalho do cientista e se vestir como cientistas em um trabalho de campo no ambiente marinho. No Espaço de Desenvolvimento Infantil Professora Solange Conceição Tricarico, a oficina foi adaptada para crianças da creche a pré-escola, com idade entre 3 e 6 anos, sendo 
DOI: $10.12957 /$ e-mosaicos.2021.47898

utilizados, principalmente, os modelos didáticos dos organismos marinhos, espécimes fixados de animais marinhos (Coleção zoológica da Seção de Assistência ao Ensino - SAE, setor educativo do Museu Nacional - MN/UFRJ), figuras, leituras e recursos como pintura e desenho.

Inicialmente, para nos aproximarmos e despertarmos o interesse do público pelo tema principal, questionamos qual o conhecimento prévio dos participantes com relação a algum(a) cientista, para que, em seguida, nos apresentemos como um(a) cientista. Para engajar os participantes na discussão do importante papel da ciência na sociedade, exemplificamos parte do trabalho que realizamos no âmbito da pesquisa em IES, descrevemos atividades de campo e de laboratório, apresentando de forma sucinta nosso dia a dia como cientistas. Durante esse diálogo, expomos utensílios que um(a) cientista marinho(a), ou seja, que trabalha com o mar, utiliza. Entre eles, materiais de mergulho autônomo como nadadeiras, máscaras de mergulho, colete e regulador de mergulho, amostradores e tubos de anotação submersíveis ${ }^{4}$., sempre possibilitando que os participantes vistam e manuseiem os materiais.

\section{REGISTRO FOTOGRÁFICO E ANÁLISE DE DADOS}

Ao longo da oficina, foram realizados registros fotográficos dos momentos de interação dos participantes, para que pudéssemos analisar diferentes dimensões de atuação do projeto e a resposta daqueles que participavam da oficina. Também analisamos a diferença das interações nas propostas pedagógicas da oficina, quando aplicadas em ambiente escolar e para o público espontâneo em feiras e eventos de ciências, na perspectiva da antropologia visual (Banks, 1998). Para tal, foi feita uma abordagem quali-quantitativa com base na análise fotográfica das interações nas oficinas realizadas. Na Oficina realizada no IBC, não foi possível o registro fotográfico tão amplo por motivos logísticos, portanto, as imagens não serão usadas na análise de interações.

As análises foram feitas no software Dedoose (Version 8.3.35, 2021), que auxilia na análise de imagens com base na codificação de cenas que apresentem atitudes e interações dos participantes. Nós avaliamos a ocorrência de atividades de leitura, interação com material didático, observação/atenção às explicações, interação com os(as) pesquisadores(as)/professores(as) e emoções. As emoções foram analisadas pelo registro de expressões faciais. Utilizando uma planilha no Microsoft Excel 2016, organizamos a quantidade com que cada tipo de interação foi observado e calculamos a porcentagem de cada interação.

${ }^{4}$ Para escrever dentro d'água, os mergulhadores utilizam lápis sobre um tubo de PVC (polímero de adição policloreto de vinila), um tipo de material usado em encanamentos de água e esgoto. 
DOI: $10.12957 / \mathrm{e}-\mathrm{mosaicos} .2021 .47898$

\section{RESULTADOS E DISCUSSÃo}

A curiosidade sobre o material utilizado em pesquisa subaquática foi fundamental para despertar o interesse do público, independente da faixa etária e do local da oficina. 0 tubo de anotação submersível foi o material mais manuseado pelas crianças de forma geral (Fig. 3), e participantes adultos que visitaram o estande do Projeto se mostraram surpresos com a possibilidade de escrever enquanto submersos. Em todos os ambientes que a oficina foi oferecida, ainda que o público fosse diferente, tanto a parte teórica quanto a parte prática foram realizadas, mantendo informações que despertassem a curiosidade e o interesse, linguagem clara e informal, recursos táteis e possíveis de manusear, associados a informações do dia a dia.

Figura 3: Aluno da pré-escola do Espaço de Desenvolvimento Infantil Professora Solange Conceição Tricarico manuseando o tubo de anotação submersível.

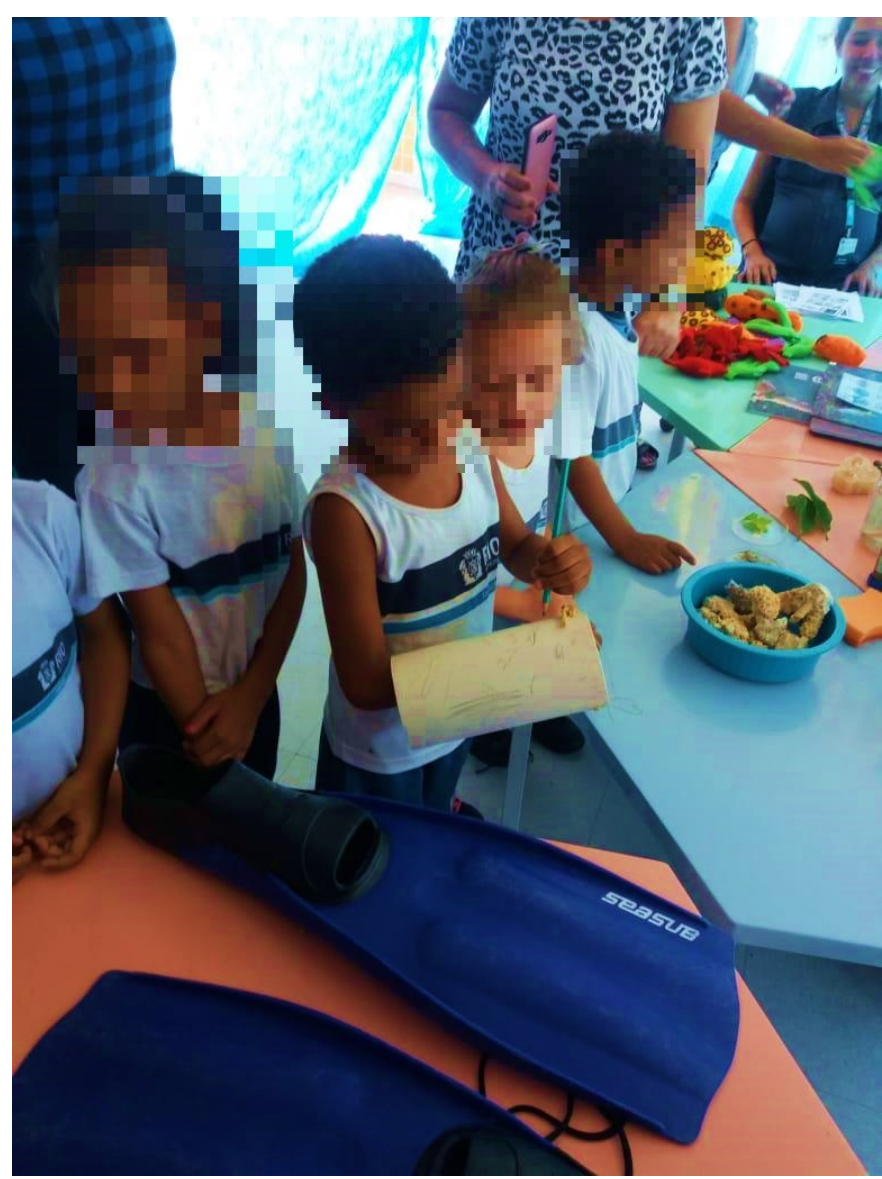

Foto: Mariana Pinto Aguiar 
DOI: $10.12957 / \mathrm{e}-\mathrm{mosaicos} .2021 .47898$

Com as figuras e os modelos didáticos mostramos parte da diversidade que existe no fundo do mar, engajamos os participantes em discussões acerca da biologia e ecologia de diferentes organismos marinhos, levantamos curiosidades envolvendo 0 comportamento e anatomia desses organismos, diferença entre grupos de animais e algas e a importância da preservação dos ambientes marinhos, como praias, costões rochosos, recifes de coral, mangues e restingas. São exemplos das questões levantadas com maior frequência: Entre os organismos apresentados, quais são animais e quais são plantas? Onde fica a boca? Como se locomovem e se alimentam? Existe animal sem olho? 0 que são e qual a importância de animais sésseis? Por que precisamos preservar 0 ambiente marinho?

Um recurso que utilizamos durante a oficina no Instituto Benjamin Constant (IBC), além dos organismos em feltro, foram tipos diferentes de esponja para manuseio e observação da diferença de uma esponja sintética, utilizada para lavar louça, uma esponja vegetal e um esqueleto de esponja marinha verdadeiro. Fizemos o mesmo com uma folha de árvore e uma alga marinha. Os alunos ficaram surpresos com a possibilidade de tocar em organismos que habitam o fundo do mar, e animados em adivinhar qual era 0 organismo e seu respectivo ambiente. Para alunos da pré-escola, tentar identificar a espécie do organismo em feltro, observando a ficha de identificação foi uma forma divertida para eles exercerem o trabalho de um cientista marinho e, ao mesmo tempo, aprender sobre cada um dos organismos e suas características básicas. Para o público que frequentou o stand durante a feira de divulgação científica, observar figuras nos livros de fotografia marinha foi um recurso importante para um diálogo não só sobre a profissão do cientista, mas sobre o ambiente marinho, a importância da preservação desses ambientes, e a biologia de alguns organismos, como por exemplo, saber que o coral é um animal e não uma planta, e a importância das algas marinhas como produtoras de oxigênio.

Quanto às interações avaliadas nas imagens fotográficas obtidas durante as oficinas, distinguimos duas modalidades oferecidas, público escolar $(n=50)$ e público espontâneo $(n=50)$. Identificamos 148 diferentes ocorrências das interações que mapeamos, sendo a observação e/ou atenção às explicações a mais recorrente $(n=53)$ seguida das interações com os(as) pesquisadores(as)/professores(as) e monitores(as) $(n=34)$ e com o material didático $(n=33)$. A leitura ocorreu em maior número nas oficinas direcionadas ao público espontâneo $(n=17)$, que incluía adultos nas interações, o que pode ser reflexo do caráter menos aprofundado da modalidade de oficina de divulgação, e como consequência, os participantes buscaram por conta própria, ler o material disponível sobre os assuntos abordados. Em contrapartida, com as crianças em ambiente escolar, as atividades participativas se destacaram, com grande número de interações com o material didático $(n=20)$ e observação das explicações dadas pelos (as) pesquisadores(as)/professores(as) $(n=35)$ (Tabela 1). Destacamos, também, as emoções, que ocorreram, apenas, no ambiente escolar $(\mathrm{N}=11)$, todas positivas, representando 
DOI: $10.12957 / \mathrm{e}-\mathrm{mosaicos} .2021 .47898$

alegria e surpresa, demonstrando que a proposta imersiva da oficina pode promover o engajamento aos temas científicos de forma lúdica, e proporcionar aprendizados a partir de respostas no campo afetivo.

Tabela 1: Proporções de ocorrência das interações observadas nas oficinas do Projeto Pra que Serve?

\begin{tabular}{lllll}
\hline Interações observadas & $\mathrm{n}$ & $\begin{array}{l}\text { Visita } \\
\text { escolar }\end{array}$ & $\begin{array}{l}\text { Público } \\
\text { espontâneo }\end{array}$ & $\begin{array}{l}\text { Contribuição } \\
\text { relativa de cada } \\
\text { interação }\end{array}$ \\
\hline emoção & 11 & $100 \%$ & & $7 \%$ \\
interação com material didático & 33 & $61 \%$ & $42 \%$ & $22 \%$ \\
interação com professoras & 34 & $56 \%$ & $38 \%$ & $23 \%$ \\
observação e/ou atenção a explicação & 53 & $66 \%$ & $34 \%$ & $36 \%$ \\
leitura & 17 & $29 \%$ & $71 \%$ & $11 \%$ \\
total & 148 & & & $100 \%$ \\
\hline
\end{tabular}

Fonte: Elaborada pelos autores

Segundo Gohn (1999), a concepção ampla de educação está associada ao conceito de cultura e apresenta perfil multidimensional relacionado à aprendizagem política de direitos coletivos e individuais e a aprendizagem de conteúdos escolares, ambos em formas e espaços diferenciados. Sendo assim, conseguimos perceber a importância de práticas sociais para o aprendizado, sobretudo, daqueles com baixo ou nenhum acesso à informação. Partindo desse pressuposto, podemos colocar como primeiro resultado relevante do projeto "Pra que serve?" o acesso de diferentes grupos sociais a conteúdos técnico-científicos, muitas vezes sendo o primeiro contato do público com o tema abordado. Não tivemos problemas de comunicação para exposição dos conceitos básicos e a estrutura da oficina se adequou muito bem aos diferentes públicos até o momento, acreditamos que o perfil prático e dinâmico tenha contribuído para a resposta positiva mencionada.

Em nossas atuações com ensino infantil, educação especial e creche fomos surpreendidas pela quantidade de perguntas e pelo envolvimento dos alunos, e recebemos mensagens de mães e de professores, reforçando a resposta que os alunos apresentaram após as atividades, principalmente, em relação ao contato com material exposto e novas informações acerca da profissão do cientista. Tivemos interessantes discussões com os alunos que questionaram: 


\section{Q}

DOI: $10.12957 / \mathrm{e}-\mathrm{mosaicos} .2021 .47898$ corais.

"Por onde ele faz o número dois?" - aluna de educação infantil se referindo a excreção dos

"Mas como ele é bicho se não tem olho"

"Você já montou em um cavalo marinho?" - aluna deficiente visual interessada e relatando a sua perspectiva sobre o tamanho dos cavalos marinhos, que, na verdade, são bem pequenos.

"Os corais são meio pedras e meio plantas né?" - aluna de ensino infantil demonstrando seu conhecimento empírico sobre animais bentônicos marinhos.

"Meu pai tem essas coisas também" - aluno de ensino infantil, identificando materiais de mergulho que são utilizados pelo pai na rotina de trabalho com pesca.

A apresentação dos materiais de mergulho autônomo, aparatos de pesquisa e os modelos didáticos confeccionados com detalhes biológicos e cores chamativas, sem dúvida, despertaram a curiosidade do público que questiona e se engaja desde o início na oficina, interessados em compreender como funcionam os equipamentos e que organismos tão diferentes estão representados ali.

Outro ponto relevante é a nossa apresentação inicial que rompe, sem dúvida, o pré-conceito em relação ao perfil do cientista que é construído no imaginário popular, figura masculina, de jaleco e óculos, que trabalha dentro de um laboratório. Ouvimos relatos como:

"Nossa! Nunca tinha visto uma cientista assim de perto."

"Você é cientista? Como faz para ser também?"

Após a oficina, os participantes demonstraram interesse na profissão do cientista marinho por meio de perguntas acerca das etapas necessárias para se tornar um cientista. Não só o público infantil, mas também os adultos durante a feira de divulgação científica se interessaram pelo trabalho e relataram o interesse pelo mergulho. Identificamos esse retorno como mais um ponto positivo na realização das oficinas, que representa uma possibilidade para muitos que não sabiam que existia essa linha de trabalho disponível. A ausência de um discurso positivo e esperançoso, o pouco prestígio da imagem social do cientista e a deficiência na comunicação pelos profissionais são alguns fatores que contribuem para a falta de motivação dos jovens para seguirem carreira profissional na área de pesquisa em C\&T (CARRAPATOSO et al. 2005). Apresentar informações sobre a profissão do cientista não só contribuiu para a divulgação científica, tornando a sociedade no geral mais informada e crítica, mas também inspirou os participantes a seguirem a carreira de cientista. 
DOI: $10.12957 / \mathrm{e}-\mathrm{mosaicos} .2021 .47898$

\section{CONSIDERAÇÕES FINAIS}

O projeto de extensão aqui apresentado busca a princípio difundir conceitos básicos de ciência e do trabalho do cientista, trabalhando no âmbito da divulgação científica com oficinas versáteis e adaptadas a diferentes públicos, sobretudo para escolas e em comunidades afastadas ou com difícil penetração em centros de pesquisa, como periferias, escolas com público majoritariamente de estudantes portadores de deficiência e em locais de risco. Até o momento, de acordo com os resultados apresentados, nosso retorno foi positivo e pudemos perceber a desconstrução de muitos conceitos prévios sobre o que é ser cientista, no Brasil, o que nos torna mais próximos do nosso público e, por conseguinte, nosso público demonstra vontade de fazer e conhecer a ciência.

É fundamental responder "O que é?" e "Pra que serve?" todo tipo de ciência bem como os cientistas. Portanto, as aç̃̃es do projeto continuarão e se aprimorarão no âmbito da extensão universitária e da divulgação científica, buscando ampliar o desenvolvimento qualitativo de práticas como essa.

\section{REFERÊNCIAS}

ALBAGLI, S. Divulgação científica: informação científica para cidadania. Ci. Inf, Brasília, v.25, n.3, p. 396-404, set./dez. 1996.

BANKS, M. Visual anthropology: Image, object and interpretation. Image-based research: A sourcebook for qualitative researchers, p. 9-23, 1998.BUENO, W. C. Comunicação cientifica e divulgação científica: aproximações e rupturas conceituais. Inf. Inf. Londrina, v.15, n.1, p. 1-12. 2010.

CARRAPATOSO, E.; RESTIVO, M. T.; MARQUES, J. C.; FERREIRA, A.; CARDOSO, R. M.; GOMES, J. F. Motivar os Jovens para as áreas da Ciência e Tecnologia, Reflexões na Universidade do Porto. In: Global Congress on Engineering and Technology Education, 2005, São Paulo.

Dedoose Version 8.0.35: web application for managing, analyzing, and presenting qualitative and mixed method research data [Computer software]. Los Angeles, CA: SocioCultural Research Consultants, LLC, 2021. Disponível em: www.dedoose.com . Acesso em: 27 fev., 2021

GOHN, M. G. Educação não-formal e cultura política. 5. ed. São Paulo: Cortez Editora, 1999. 128 p.

MARANDINO, M. et al. A educação não formal e a divulgação científica: o que pensa quem faz? In: Encontro Nacional de Pesquisa em Ensino de Ciências, 2004. Bauru. 
DOI: $10.12957 / \mathrm{e}-\mathrm{mosaicos} .2021 .47898$

MARANDINO, M. Educação em museus: a mediação em foco. São Paulo: GEENF FEUSP, 2008. 48p. Disponível em: http://moodle.stoa.usp.br/file.php/661/A mediacao em foco.pdf. Acesso em: 26 fev., 2021.

MOREIRA, M. A. Pesquisa básica em educação em ciências: uma visão pessoal. Rev. Chil. Educ., La Serena, v.3, n.1, p. 10-17. 2004.

SALA, O. O papel da ciência na sociedade. Rev. Hist., São Paulo, v.50, n.100, p. 813-820. 1974.

SCHWARTZMAN, S; CHRISTOPHE, M. A educação em ciências no Brasil. Rio de Janeiro: Instituto do Estudo do Trabalho e Sociedade, 2009. 118 p. Disponível em:

http://www.abc.org.br/IMG/pdf/doc-210.pdf . Acesso em: 27 nov. 2019.

SMITH, M. K. What is non-formal education? In: infed.org: education, community-building and change. The encyclopedia of pedagogy and informal education. 1996. Disponível em:

http://www.infed.org/biblio/b-nonfor.htm . Acesso em: 11 nov. 2019.

TOSTES, R. A. A importância da divulgação científica. Rev. Acad., Curitiba. v.4, n.4, p. 73-74. 2006.

VELHO, R. A ciência e a tecnologia no olhar dos brasileiros. Cienc. Cult, São Paulo. v.69, n.4, p. 10-13, out./dez. 2017.

Recebido em 21 de janeiro de 2020

Aceito em 18 de março de 2021

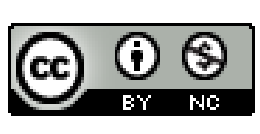

A e-Mosaicos Revista Multidisciplinar de Ensino, Pesquisa, Extensão e Cultura do Instituto de Aplicação Fernando Rodrigues da Silveira (CAp-UERJ) está disponibilizada sob uma Licença Creative Commons - Atribuição - NãoComercial 4.0 Internacional.

Os direitos autorais de todos os trabalhos publicados na revista pertencem ao(s) seu(s) autor(es) e coautor(es), com o direito de primeira publicação cedido à e-Mosaicos.

Os artigos publicados são de acesso público, de uso gratuito, com atribuição de autoria obrigatória, para aplicações de finalidade educacional e não-comercial, de acordo com o modelo de licenciamento Creative Commons adotado pela revista. 